\title{
¿Qué pasó con Dios? ¿Qué pasó con el hombre? Sobre la situación del cristianismo en la Europa secularizada
}

\author{
Johann Baptist Metz. \\ Universidad de Münster, Alemania.
}

El cristianismo está haciendo, en la actualidad, el ensayo de convertirse en un auténtico cristianismo universal. Comprometido durante casi dos milenios con un ámbito cultural relativamente homogéneo, el europeo-occidental, se está expandiendo ahora hacia un cristianismo universal de raíces culturales múltiples. Se encuentra en una cesura de su historia, quizás la más profunda e incisiva que haya vivido desde sus origenes. Está en camino de convertirse de un cristianismo relativamente homogéneo en el aspecto cultural, es decir, el cristianismo culturalmente monocéntrico de Europa y Norleamérica, en un cristianismo de múltiples rafces culturales y, en este sentido, culturalmente policéntrico.

En el curso de los últimos aflos he tratado de destacar, ante todo, las promesas inherentes a este movimiento de búsqueda del cristianismo, es decir, los indicios de que se está produciendo ya un intercambio mutuo entre las Iglesias extraeuropeas y las europeas. Asi, por ejemplo, la profecía de las iglesias pobres del tercer mundo está siendo escuchada, en grado creciente, también en el antiguo centro europeo del cristianismo; la teología de la liberación constituye un proyecto legitimo y necesario de la teologla postidealista. También he llamado la atención sobre el significado ecuménico de ese éxodo, no sólo en lo concerniente al ecumenismo intracristiano, sino, especialmente, en lo que se refiere también a la relación entre cristianos y judíos, entre la Iglesia y sinagoga. 


\section{I}

En lo sucesivo me propongo tratar más explícitamente que hasta ahora toda la complejidad y, en cierto modo, la contradicción interna que encierra este movimiento de búsqueda encaminado hacia un cristianismo policéntrico. Y mi punto de partida será la pregunıa de si ese éxodo del cristianismo europeo hacia un cristianismo universal, culturalmente policéntrico, es realmente un movimiento de búsqueda sustentado por la esperanza cristiana o si es, quizás, tan sólo un movimiento de huída, encubierta teológicamente, para escapar de la miseria y de la falta de futuro del cristianismo europeo. En palabras de nuestros amigos teólogos del Tercer Mundo esto se suele expresar aproximadamente en los siguientes términos:

Ustedes, los cristianos de la vieja Europa, dan la impresión de árboles deshojados; ya no tienen visiones. Déjennos al menos las nuestras...

Electivamente cabe preguntamos: nosotros, los cristianos europeos ilenemos algo que ofrecer, además de dinero y buena voluntad y, por lo demás, manos vacías? ¿No tratamos de refugiamos en los milos de países y culturas remotas para llenar esas manos vacías? Y todo esto, para colmo, en una época en que muchos de los que en un momento dado habían renegado de Europa se encuentran ya en el viaje de retomo al viejo occidente.

Para que el éxodo hacia el cristianismo universal, culturalmente policéntrico, no se convierta en huída, en mera compensación mílica de esperanzas perdidas, hay que plantearse con una perentoriedad apenas conocida hasta ahora la cuestion de cuál habrá de ser el destino del cristianismo europeo. A continuación quisiera ilustrar este planteamiento con dos reflexiones y descle dos perspectivas.

La primera consideración parte de una rellexión teológica crítica. Esta va dirigida contra un malentendido muy difundido, relacionado con la idea del enraizamiento del cristianismo en culturas no occidentales, es decir, con lo que hoy en día se discute en el cristianismo bajo el concepto de "inculturación." El bienintencionado intento de proteger la universalización real del cristianismo contra conclusiones erróneas de carácter etnocéntrico, para impedir, por así decirlo, una segunda y tardía toma del poder por parte de Europa dentro de cristianismo mundial, va acompañado a menudo de propuestas del siguiente tenor. el cristianismo debera desprenderse, por fin, de su ropaje europeo, despojarse definitivamente de su envoltura europeo-occidental, etc. Subyace a esto la idea de un cristianismo sin historia, élnicamente inocente y ajeno a todo vínculo cultural; la idea de un "cristianismo al desnudo," que, en un principio, estaria arropado meramente en sí mismo y sólo a posteriori se revestiría de los diversos ropajes culturales. Esta idea, sin embargo, es una ficción que se alimenta del discurso metafórico irreflexivo de los "hechos desnudos" o la "verdad al desnudo." No se puede deshojar culturalmente al cristianismo sin renunciar a su identidad, de la misma manera que no se pueden 
arrancar todos los pétalos de una rosa sin destruirla. Las culturas no son la herrumbre que se puede desprender del hicrro del cristianismo para recuperarlo reluciente. No es posible un cristianismo culturalmente desvestido, desnudo. "Jesús no fue cristiano, sino judío." Quicn sólo conoce el cristianismo, en realidad, no lo conoce cabalmente. La cultura que el cristianismo no puede anancarse del cuerpo es la cultura europeo-occidental, surgida de la asimilación de tradiciones judeopalestinas y greco-helenísticas. La interrogante de cómo, con tales premisas, puede existir un crisianismo universal, culturalmente policéntrico, y una inculturación que no sea meramente una expansión occidental encubierta por razones tácticas, recae sobre el cristianismo europeo-occidental.

Una respuesta prometedora a csta interrogante depende de varias condiciones, que quisiera esbozar brevemente. Por una parte, es importante que el cristianismo europeo reconozca la historia de pecado, que, desde hace siglos, lo vincula con muchos de esos pueblos y culturas no europeos. Si esta historia de culpas se niega o se silencia por razones tácticas, nuestra ayuda al desarrollo, provenga del Estado o de las iglesias, se convierte en mera prolongación de la colonización europea por medios pacíficos.

Por otra pare, el cristianismo - que no puede desprenderse sin más ni más de su historia europea - sólo podrá convertirse en culturalmente policéntrico si recuerda y reaviva dos rasgos fundamentales de su herencia: si, partiendo de su legado bíblico, se comprende a sí mismo como un cristianisno que busca la libertad y la justicia para todos, y si se comprende a sí mismo como un cristianismo que desarrolla en sí una cultura específica: la cultura de la aceptación del otro en su ser ouro, o sea, el reconocimiento creativo de la pluralidad étnico-cultural, que debiera sernos familiar desde la historia de los orígenes del cristianismo. En términos del lenguaje usual hoy en día, pudiéramos decir que el cristianismo debe desarrollar en su seno dos opciones: una opción por los pobres y una opción por los otros en su ser otro. El cristianismo debe concretizarse en una cultura política de libertad y justicia, y en una cultura política del reconocimiento de los otros en su alteridad.

El proceso de un policentrismo cultural en el cristianismo también plantea nuevas tareas a la tcología. En esta situación de transición, la teología debe examinar, por ejemplo, la fuerza comunicativa de sus enunciados y desarrollar lo que podría llamarse "categorías puente," es decir, categorías de mediación intercultural. Porque el cristianismo es, por su origen, una comunidad que vive del recuerdo y de la narración en el seguimiento de Jesucristo, y precisamente como comunidad con estas características, parece ser altamente comunicativa en el ámbito intercultural, es decir, capaz de inculturación. Para ello, la teología debe tratar de recalcar en forma innovadora la dignidad comunicativa del recuerdo y de la narración.

Es cierto que esos recuerdos y esas narraciones de la fe no tienen un significado meramente literario, sino histórico: son la expresión de una rememoración histórica. Invocan, ante todo, la memoria de los sufrimientos. A través de esa me- 
moria de pasión, el cristianismo trata de establecer un nexo con la sabiduría y las experiencias de sufrimiento de otras culturas. De esta manera se va preparando una asimilación mutua y creativa de los ámbitos culturales. Esta asimilación creativa de las difcrentes culturas conslituye presumiblemente el progreso auténtico de la humanidad en su conjunto; en todo caso, representa una importante premisa para la paz mundial. Cabe preguntarse entonces si el cristianismo, que va madurando hacia un policentrismo cultural, podrá ser un ejemplo productivo para el trabajo en pro de la paz. Con esta interrogante pongo punto final a mi primera reflexión.

La segunda reflexión, que nos remite a la situación del cristianismo europeo, tiene primordialmente carácter empírico. En el curso del siglo pasado, Europa en cierto modo se ha universalizado, adquiriendo dimensiones mundiales. Lo ha hecho a través de esa europeización profana del mundo entero, que llamanos "ciencia" y "técnica" o también "civilización tecnológica;" es decir, a través de la así llamada "racionalidad occidental," que con su "desencantamiento del mundo" ejerce entretando un dominio universal.' A este respecto nosotros, los europeos, en los últimos tiempos hemos tenido que hacer una experiencia grata para algunos, sorprendente para otros, y decepcionante y frustrante para muchos otros: la experiencia de que los pueblos y las culturas extraeuropeas parecen acomodarse con excesivo celo a la europeización de su mundo. Este comportamicnto adaptativo, del que hay numerosos síntomas, suscita la duda de si el policcntrismo cultural en nuestro mundo no lleva ya en sí el germen de su propia descomposición y si, en general, existe aún suficiente idenlidad y resistencia cultural frente a esc proceso universal de la civilización europea, con sus innegables progresos, pero también con sus mitos del progreso. ¿Acaso, al final, todo el progreso y toda la liberación de esos países no será sino una especie de liberación orientada hacia occidente? Así, pues, al plantearnos la cuestión acerca de la capacidad del cristianismo de forjar su propio futuro, ¿nos veremos una vez más replegados sobre nosotros mismos, dado que nosotros, que durante algún ticmpo habíamos creído que el mundo extracuropeo sería nuestro porvenir, subrepticiamente nos hemos convertido precisamente en el luturo de ese mundo no europeo? ¿Debemos, por lo tanto, extraer la visión del futuro del cristianismo antes que nada también de nuestra antigua herencia europea? Asi parece en efecto.

\section{III}

Pero ¿cómo se presenta la siluación del cristianismo europeo (de este y del otro lado del Alántico)? ¿Qué está ocurriendo en Europa?

Partamos, de nuevo, del proyecto mundial, al cual acabo de relcrime, es decir, el proyecto de la civilización científico-técnica, que ha adquirido hoy en día dimensiones globales. El cristianismo no puede considerar este proyecto europeo simplemente como un catalizador neutral para su propia difusión a escala mundial. 
Es demasiado evidente que este proyecto europeo tardío encierra también gravísimos riesgos para el cristianismo. ¿No fue acaso en esta Europa tardía, donde por primera vez se pregonó públicamente la "muerte de Dios"? Y ¿no es en esta misma Europa donde se nos viene preparando desde hace bastanle tiempo para la "muerte del hombre," tal como lo conocemos a través del curso de nuestra historia?

Los procesos de la modernidad europea, que han conducido a la europeización profana del mundo, no son tan sólo procesos de secularización, en el sentido de fenómenos de desposesión y desintegración de la religión. Cada vez en mayor medida se dan a entender como procesos de desposesión y desintegración del hombre, tal como éste, hasla ahora, nos era conocido y nos había sido encomendado. Parecería que el hombre es cada vez menos su propia memoria y cada vez más lan sólo su propio experimento. Todo se toma técnicamente reproducible; al final, incluso el propio hombre productor. Parece que, al menos, se puede generalizar la siguiente constatación sin pecar de excesivo pesimismo cultural: los procesos europeos de modemización, en la medida en que se abandonan en forma no dialéctica al avance supuestamente gradual del progreso, no fortalecen realmente al hombre en su ser sujeto, en su capacidad de interrelación humana y su conciencia histórica, sino más bien lo debilitan en lodos estos aspectos.

El principio mercantilista y de trueque de esta civilización hace tiempo que ha rebasado al ámbito económico y ha afectado las bases espirituales de nuestra sociedad, colonializando los corazones de los hombres a su manera. Parece que todo se ha vuelto intercambiable, incluyendo las relaciones interpersonales. También nuestra memoria histórica se rige cada vez menos por la responsabilidad moral y cada vez más, en cambio, por una inocencia que se hace pasar por objetividad. La aceleración veriginosa en que vivimos, el cambio precipitado en el consumo y las modas, incluyendo las de tipo cultural, apenas permiten ya una percepción sensorial. Nuestras percepciones se vuelven cada vez menos concretas, menos sensoriales, porque tanto a los hombres como a las cosas por regla general únicamente los podemos seguir con la mirada una vez que pasaron, viéndolos, por así decir, solamente por la espalda. De esla manera, el individuo es adiestrado cada vez más para adaptarse a un mundo inexpresivamente abstracto e inabarcable. También parece bloqueado el recurso a las fantasías infantiles, porque éstas las hemos asfixiado con nuestros juguetes automáticos aun antes de que pudieran desarrollarse.

¿Qué pas6, pues, con "el hombre"? Parece que éste sobrevive tanto más exitosamente, cuanto más se somete a un proceso de involución que lo lleva a convertirse en un animal mantosamente adaptable. En Estados Unidos ya ha comenzado la licitación pública para elegir a un sucesor del hombre. La revista neoyorkina Time lo ha retratado como "hombre del año" en una de sus portadas de los últimos antos: el robot, una máquina que funciona dócilmente y sin contradicciones, una inteligencia computarizada, que ya no puede recordar, que no la amenaza ningún olvido; una inteligencia sin historia, sin capacidad de sufrimiento y sin moral. Aquellos a quienes esto les suene a ciencia ficción deberian leer al menos el libro reciente de Robert Bellah Habits of the heart, en el cual describe la socie- 
dad de Estados Unidos como una sociedad de creciente mutismo, aislamiento y ausencia de relaciones, precisamente porque en ella los hombres no están solos en ninguna parte, porque en sus viviendas, enlazadas por redes de comunicación por cable, y en sus puestos de trabajo, interconectados por medios electrónicos, viven constantemente "en la masa" y "como la masa."

Esta mucrte insidiosa y mansa del hombre se operará tanto más eficazmente cuanto menos la experimentemos como amenaza y opresión, sino mas bien como diversión y entretenimicnto. De ello se encargan nuestra modema industria de la cultura y el predominio creciente de los medios masivos de comunicación; entre éstos, especialmente la televisión, que envuelve cada vez más nuestra vida cotidiana en forma cuasitrascendental, exonerándonos más y más de la carga de nuestras imagenes, nuestros sucños, nuestras historias y nuestro lenguaje propios, para convertimos algún día en analfabetos experimentados y felices. El escritor alemán H. M. Enzensberger ya ha detectado entre nosotros este "analfabeto secundario," como él lo llama, describiéndolo de la siguiente manera: "El analfabeto secundario vive bien: porque él no sufre por la pérdida de la memoria que padece; caracer de voluniad propia lo alivia; sabe apreciar su incapacidad de concentrarse y estima ventajoso el hecho de no saber ni comprender lo que sucede. Es ágil, adaptable. Tiene considerable capacidad para hacer valer sus intereses. Así, pues, no debemos preocuparnos por él. El hecho de que el analfabeto secundario no tiene la menor idea de que lo es contribuye a su bienestar. Se cree bien informado; es capaz de descifrar instructivos de uso, pictogramas y cheques, y se mueve en un entorno que lo protege herméticamente contra cualquier inquietud de su autoconciencia. Es inconcebible que pueda fracasar en relación con el mundo que lo rodea, ya que éste lo ha generado y conformado para garantizar su propia persistencia inalterada. El analfabeto secundario es el producto de una nueva fase de la industrialización."

Estos serían, pues, algunos parámetros de la época europea que es todavía modema o ya postmodema: el hastío de ser sujeto, una especie de segunda "infancia," la pérdida de memoria, la desintegración del lenguaje y, por encima de todo, el adiós a la historia, porque si examinamos críticamente esta nueva afición por la historia, que últimamente se está encomiando entre nosotros, veremos que es ante todo un gusto por la literaturización de la historia. "La historia se ha convertido íntegramente en literatura, en la cual uno elige a la carta lo que a uno le gusta: la nouvelle cuisine de la posthistoire." Los mitos volvieron a ser digeribles, particularmente si llegan a nuestra mesa procedentes de países no cristianos; el sujeto crítico, que durante demasiado tiempo se atragantaba con ellos, se encuentra de todos modos en eslado de disolución.

Pero, ¿nо suena todo esto a una crítica cultural elitista y ligeramente remilgada, frente a los peligros reales, como por ejemplo, la amenaza real que la bomba atónica representa para la humanidad? No creo que así sea. Porque esa realidad, ese peligro real, ¿lo percibimos, efectivamente, cada vez mas? ¿O... cada vez menos? ¿No estamos más bien amenazados por una pérdida masiva de la percepción de la realidad? ¿No es que, acaso, la "realidad" se escribe cada vez más entre comi- 
llas? Pernílaseme ilustrar esto con una observación cotidiana de mi país. Allí se difunde una scrie de televisión que goza de gran popularidad y que lleva el título de La clínica de la Selva Negra. Hace liempo ya que en Alemania el número de personas que peregrinan al lugar donde se ha rodado esta serie rebasa ampliamente el número de los peregrinos motivados por impulsos religiosos (y seguramente no faltará mucho para que supere la cifra de los que día a día hacen cola ante los mausoleos políticos en los países del bloque oriental). Prospera el culto de lo imaginario. ¿Scrá que en Europa vivimos ya en un mundo exclusivamente simulado, como suponía el francés Baudrillard? ¿No se hace al menos cada vez más difícil distinguir entre el mundo natural de la vida y el mundo, reproducido artificialmente, de los medios masivos de comunicación? ¿No se confunden la realidad auténtica y la realidad reproducida en imágenes de una manera cada vez más difícil de diferenciar? Y lo que nosotros tomamos por realidad, ¿no será, al fin de cuenlas, nada más que su réplica reproducida por medios artificiales? ¿Cómo es que el personaje que dirige la clínica en la mencionada serie de televisión recibe diariamente cartas en las cuales se le solicitan consejos médicos? ¿Scrá esto sólo un episodio, o se trata de todo un síntoma? Procesos de esta índole adquieren, en todo caso, carácter sintomático cuando pueden observarse con creciente frecuencia en el seno mismo de nuestras empresas modernizadoras y de nuestros centros de información. Asi, por ejemplo, se sabe que entre el personal de la gran empresa francesa de computación Compagnie Générale de l'Information es mayor el número de adeplos a la oscura secta de los Rosacruces que el de afiliados sindicales. Triunfa el culto de lo imaginario. La percepción de la realidad decae; no por falta de información, sino por exceso de la misma. Y la calástrofe no consiste en lo que ésta es, sino en el hecho de que ya no logramos percibirla como tal, convirtiéndonos cada vez más en mirones de nuestro propio ocaso.

Por lo demás, parece como si la bomba de neutrones ya hubiese estallado en muchas cabezas, como si la muerte del hombre en medio de sus circunstancias, inlactas en los demás aspectos, fuera un hecho consumado desde hace tiempo por las ciencias modernas. Por lo visto, nuestros modemos conocimientos científicos no se interesan por las bases subjetivas del saber; hablando con propiedad científica, el sujeto, al igual que la libertad, el individuo, etc., son meros antropomorfismos. Contra la objeción de que tal afirmación resulta bastante fría y abstracta, cl filosofo francés M. Foucault, cuya inlluencia póstuma va en constante aumento, aduce: "¿Abstracto? Yo respondería diciendo: es el humanismo, el que es abstracto. Y todos esos clamores del corazón, todos esos anhelos de la persona humana y de la existencia son abstractos, es decir, desligados del mundo científico y técnico que es nuestro mundo real... Por ello, el intento que actualmente emprenden algunos de nuestra generación, no consiste en defender al hombre frente a la ciencia y la técnica; sino en mostrar claramente que nuestro pensamiento y nuestra vida, toda nuestra manera de ser, hasta nuestro comportamiento más cotidiano, son parte del mismo esquema organizativo y por ende dependen de las mismas categorias que el mundo científico y técnico. Lo abstracto es el 'corazón humano."' 
Según esto, lo que candorosa e ingenuamente llamamos "el ser humano" sería, desde hace tiempo un anacronismo. Ese ser humano, si es que alguna vez lo hubo, ya no existe en realidad. Para estar al tanto de lo que ocurre, hay que partir de su muerte. Al menos entre los pensadores franceses, esta muerte del hombre se da por descontada. Y la meticulosidad alemana ya la ha explicado y clasificado en términos de la teoría de sistemas: no existen sujetos, tan sólo sistemas autocontenidos. En ellos no rige la espontaneidad del espíritu (iqué idca tan al estilo de la "vieja" Europa!...), sino la frialdad sideral de una evolución infinitamente indiferente. Todo lo que recuerda al hombre que fuimos en el pasado cs, en todo caso, una angustia amorfa, ajena a toda percepción y acción. ¿De qué nos sirve entonces que se nos asegure que esa "muerte del hombre" no es más que un concepto "puramente epistemológico," propio "únicamente de la teoría de las ciencias"? ¿De qué nos sirve esto en un mundo en que, a través de la técnica, las ciencias se vuelven totalmente prácticas y, de esta manera, no sólo describen, sino definen también lo que es real?

¿Qué nos queda, pucs, por hacer a los europeos? ¿Volver una vez más la espalda a Europa? ¿Buscar refugio en la vida agitada? ¿O acogemos nuevamente a la vida apacible, inocente y ahistórica del helenismo mediterráneo de la era precristiana, tal como lo recomiendan con grandes alardes de erudición algunos profetas, aficionados a los mitos, de la lamada postmodernidad? ¿ O bien resignarnos, empequefieciéndonos instintivamente y aceptando una vida sin grandes certidumbres, a escala reducida, con un pensamiento de nicho ante el presentimiento del peligro? ¿O acaso, si, emprender la lucha por reavivar la herencia judeo-cristiana en nuestro mundo europeo-occidental? Una lucha por la capacidad del cristianismo de forjar su propio futuro, de ese hombre que nos es historicamente conocido y que nos ha sido encomendado. Sólo si esto se logra, el espíritu europeo podrá, en mi opinión, superar los peligros que él mismo ha suscitado. Porque, a fin de cuentas, también en esta Europa secularizada estamos empeñados en un movimiento de búsqueda: no un movimiento necio y arrogante en pos de la abolición de nuestro mundo científico-técnico y de sus logros, ni inspirado por el deseo imprudente de una eutanasia de la técnica en sí misma; pero sí, en cambio, orientado hacia nuevas formas del manejo de la misma, con conciencia del trasfondo cultural de nuestra racionalidad tecnológica, porque no queremos confiar en que el proceso evolutivo de modernización garantice, por sí mismo y por sí solo, un futuro digno del hombre; porque sabemos que no sólo producimos progresos, sino también mitos del progreso. Antes de preguntamos, pues, si las culturas extraeuropeas nos pueden olrecer reservas de orientación y resistencia, nosotros, los europeos, deberíamos invocar y dar vida a nuestra propia herencia.

Esto es precisamente lo que nosotros, como europeos, les debemos también a los cristianos no europeos, particularmente a las iglesias pobres del tercer mundo y a sus propósitos de liberación. Porque la europeización profana del mundo por conducio de la técnica y la industria de la cultura no se ha detenido ante esos países y sus respectivas culturas. Esta segunda esclavización hace tiempo que opera 
con todo éxito. Y es entre esos pucblos donde el terrorismo sutil de la industria de la cultura surte efectos aún más letalcs que entre nosotros en Europa. Es él el que paraliza todo proceso de liberación. Desde hace tiempo el opio de los pobres ya no es la religión. Es la cultura de los medios masivos de comunicación la que hace que esos hombres se harten de ser sujetos antes de haberse convertido en sujetos de su propia liberación. Es precisamente esa industria de la cultura la que -apenas hayan adquirido concicncia de su propia pasión- los vuelve a despojar de la memoria y amenaza su lenguaje, antes de que ellos se hayan podido articular y alfabetizar. La resistencia contra la desintegración del hombre, de su historia y su lenguaje, sería una especie de tarea de liberación para todos; no la única, pero tampoco la más insignificante. Pero ¿cómo realizarla?

\section{IV}

Todo dependerá del horizonte dentro del cual Europa se ilustre accrca de sí misma y de su propio estado. Creo que existe a esie respecto una clara alternativa, que - a mi modo de ver- se puede explicar de la manera más breve recurriendo a un pensador que ha adquirido una actualidad totalmente nueva en la vida intelectual europea: me reficro a Fricdrich Nictzsche. Quisiera señalar que casi todos los europeos que levantan el acta de la "muerte del hombre" se conceptúan a sí mismos como discípulos de Nielzsche, el más radical de los profetas de una era postcristiana. Bien vale la pena indagar en su obra; averiguar de qué se trata. Usualmente lo cilamos como el pregonero de la muerte de Dios en el corazón del occidente europeo. Al hacerlo, sin embargo, olvidamos a menudo que el propio Niezzsche deduce una consecuencia inexorable de esa muerte de Dios: a saber, la muerte del hombre, de ese hombre, como el que hasta ahora conocemos y nos ha sido encomendado. Porque también Nietzsche habla ya de la muerte del sujeto. El considera al sujeto como mera "ficción" y al discurso del "yo" como simple antropomorfismo. Y él también describe ya la desintegración definitiva del lenguaje en el Irenesi de las metáforas carentes de sujeto; basta con leer, a este respec10, su breve escrito Sobre la verdad y la mentira en sentido extramoral.

También sostiene ya que la historia, desligada de la eternidad, se precipita en una evolución anónima, que no pretende orra cosa más que eso: evolución, una concinuidad vacía, desprovista de sorpresas, que crece hasla el infinito, y que en forma inexorable va englobando todo y a todos y cualquier expectativa substancial. Nietzsche, sin embargo, aún conoce la hipótesis de fondo de esa muerte del hombre, y la señala: la muerte de Dios. El sabe cuál es el eco que responde al grito de su "hombre enloquecido:" ¿Qué pasó con Dios? Ese eco dice: ¿y qué paso con el hombre?

Por ello me atrevo a formular aquí, en forma drásticamente abreviada, la conclusión inversa: quien quiera resistirse a la extinción del hombre, quien quiera im- 
pedir su muerte, mansa o dramática, quien quiera salvar a ese hombre que nos es conocido y nos ha sido encomendado, y con él su identidad como sujeto, sus posibilidades de entendimiento, su memoria y su insaciada hambre y sed de justicia, cuando llegue la hora de la verdad sólo lo logrará por la fuerza de la memoria de Dios. Y lo que debería tomar muy en cuenta esa época modema aún o ya postmoderna, tan comprometida como está con la muerte del hombre, es lo subversivo de esa memoria de Dios, que aún hoy en día nos hace hablar de humanidad y solidaridad, de alienación, opresión y liberación, y que nos impulsa a luchar contra la injusticia que clama al cielo, contra la depauperación y la miseria destructora. Por cierto que en Foucault, ese gran precursor de la postmodernidad europea, se advierte todavía, en clave, ese nexo entre la rememoración de Dios y el recuerdo del hombre cuando alude a la expresión de Holderlin sobre la "ausencia de Dios," escribiendo al final de su Arqueologla del saber: "Bien podría ser que hayan matado a Dios con el peso de lodo lo que han dicho. Pero no crean que con todo lo que dicen harán un hombre que viva más que él."

En este pasaje me llama particularmente la atención el énfasis puesto en el lenguaje ("lo que han dicho... lo que dicen...") Por lo visto, al tratar de la muerte de Dios y la muerte del hombre se trata de discurso, de lenguaje. "¿Quién habla?" es, asímismo, la pregunta inicial de quienes salen al ruedo con la intención de demostrar que no existen los sujetos atribuidos al lenguaje: ni sujetos divinos, ni humanos. No existen sujetos, afirman; sólo discursos atribuibles a sujetos. Me pregunto si toda nuestra tan erudita semántica y semiótica estructuralista y postestructuralista no estará empleando, quizás, un enfoque altamente dudoso. El cristianismo, al menos, recomienda un replanteamiento de la pregunta inicial. Para el crislianismo, la pregunta inicial no reza ¿quiên habla?, sino ¿quién sufre? De esta forma procede la religión cuando pregunta por sujetos, y también cuando pregunta por el lenguaje del hombre. Porque para la religión el lenguaje, el logos, no pertenece en primer lugar a los que piensan, sino a los que sufren.

Por ello, el lenguaje fundamental de la oración es, ante todo, un lenguaje de los que sufren. Y el lenguaje de la oración, como lenguaje de quienes sufren, no es un lenguaje de respuesta consoladora al sufrimiento, sino de pregunta no consolada que brota del sufrimiento. Esta pregunta a Dios en la oración es, a mi manera de ver, una expresión última "del hombre" a través del lenguaje que parece haberse perdido desde hace tiempo para nuestra autoconciencia más avanzada.

En otro aspecto más, el cristianismo posee una memoria salvadora para el hombre. La memoria de Dios del cristianismo es, en su esencia, una memoria de pasión: la memoria de sufrimientos no expiados, que con nada se puede aquietar. En medio de nuestros procesos de modernización, el cristianismo formula la pregunta (implícita en la confesión de la resurrección de los muertos y del juicio) por la justicia para los que sufren injustamente, por todos los sacrificios no expiados y por todas las victimas de la historia, como una rememoración peligrosa con la cual trata de romper el hechizo de nuestros mitos de progreso como una categoria de la redención del hombre. Porque cuando hacemos desaparecer los 
sufrimientos pasados en el abismo de una evolución anónima, al fin de cuentas nos proyectamos nosotros mismos como seres sin sujeto, como juegos superficiales sobre las olas de esa evolución. Sin esta rememoración se opera, ora mansamente, ora en forma dramálica, aquella muerte del hombre y aquella paralización de su historia de las que se ha hablado extensamente en esta reflexión. Lo cierto es que, sin esta rememoración, el futuro del hombre se vuelve cada vez más dudoso.

Por ello, el cristianismo exige, una y otra vez, de nuestra autoconciencia pública esa pregunta por los sufrimientos irrevocables pasados, para salvar a los vivos y rescatar en ellos el sentido de una justicia y liberación indivisas.

Entre nosotros, en Europa, se habla mucho de que vivimos en una "era postcristiana," queriendo significar con ello probablemente una época en que al cristianismo ya sólo se lo ve por la espalda: lo dicen con tristeza algunos, temerosos otros, indiferentes la mayoría. En realidad, también en Europa seguimos en una época en la cual no debe verse al cristianismo por la espalda, sino a la cara, si todavía queremos hablar de un posible futuro del hombre y de la humanidad. 